\title{
Desafios da Capes na condução da Política Nacional de Formação de Professores da Educação Básica
}

\section{Challenges faced by Capes in conducting Pre-Tertiary Education Teachers National Training Policy}

\section{Retos de Capes en el desarrollo de la Política Brasileña de Formación Pedagógica de Maestros de la Enseñanza Básica}

http://dx.doi.org/10.21713/2358-2332.2016.v13.1262

Valdinei Costa Souza, doutora em Educação pela Universidade de Brasília (UnB) e analista sênior em Ciência e Tecnologia da Coordenação de Aperfeiçoamento de Pessoal de Nivel Superior (Capes), Brasília, DF, Brasil. E-mail: valdinei.costa.souza@gmail.com.

\section{Resumo}

O objetivo deste ensaio é instigar o debate sobre o papel da Coordenação de Aperfeiçoamento de Pessoal de Nivel Superior (Capes) na condução da Política Nacional de Formação de Professores da Educação Básica. Para tanto, analisa as atas do Conselho Técnico Científico da Educação Básica (CTC-EB), por meio da hermenêutica, destacando as decisões estratégicas da Capes na condução dessa política. Como resultado, apresenta os desafios que a Capes precisará enfrentar para simultaneamente: a) cumprir a nova missão que Ihe foi imputada no contexto da formação de professores da educação básica; e b) manter a identidade institucional, por ela construída, no âmbito dos seus programas tradicionais de formação de pessoal.

Palavras-chave: Política Educacional. Capes. Formação de Professores. 


\section{Abstract}

This essay proposes to discuss the role of the Brazilian Federal Agency for Support and Evaluation of Graduate Education (Capes) in the conduct of Pre-Tertiary Education Teachers National Training Policy. To that end, the hermeneutical approach was used to analyze the minutes of the Brazilian Technical-Scientific Council of Pre-Tertiary Education (CTC$E B)$. As a result, the challenges that Capes will have to face in order to, simultaneously, (a) fulfill the new mission assigned to it in the context of basic education teacher training; and (b) maintain the institutional identity it has built within its traditional staff training programs, are summarized.

Keywords: Educational Policies. CAPES. Teacher Training.

\section{Resumen}

El propósito de este ensayo es instigar el discusión sobre el papel de la Coordinación de Perfeccionamiento de Personal de Nivel Superior (Capes) en la conducción de la Política Nacional de Formación Pedagógica de Maestros de la Enseñanza Básica. Para eso, se analizaron, por medio de la hermenéutica, las actas del Consejo Técnico-Científico de la Enseñanza Básica (CTC-EB), destacándose las decisiones estratégicas de Capes en la conducción de esa política. Como resultado, el ensayo resume los retos que Capes tendrá que afrontar para simultáneamente: (a) cumplir la nueva misión que se le asigna en el contexto de la formación de maestros de educación básica; y (b) mantener la identidad institucional que ha construido en el ámbito de sus programas tradicionales de capacitación de personal.

Palabras clave: Política Educativa. CAPES. Formación de Maestros.

\section{INTRODUÇÃO}

A Lei $n^{\circ}$ 11.502, de 11 de julho de 2007, agregou a indução e 0 fomento à formação inicial e continuada de profissionais de magistério 
da educação básica à missão da Coordenação de Aperfeiçoamento de Pessoal de Nível Superior (Capes) após exatos 56 anos de sua criação. Desde então, a Capes passou a atuar como uma grande agência formadora, responsável por subsidiar o Ministério da Educação (MEC) na formulação de políticas e no desenvolvimento de atividades de suporte à formação de profissionais de magistério para a educação básica e superior, bem como para o desenvolvimento científico e tecnológico do país (BRASIL, 2007).

Tradicionalmente, a Capes sempre atuou na formação de professores para a educação superior, além da formação de outros profissionais de alto nível para o desenvolvimento da ciência, da tecnologia e da inovação no país. Visando garantir a qualidade dessa atuação, desenvolveu o sistema de avaliação de cursos de mestrado e doutorado, associando-o à execução de programas de fomento. Grosso modo, a atuação da Capes, por meio da avaliação de cursos e o fomento à pósgraduação e à pesquisa, vem contribuindo para a consolidação, qualidade e produtividade do Sistema Nacional de Pós-Graduação (SNPG).

Assim, quando a Capes passou a assumir também o desafio de atuar na formação de profissionais da educação básica, esperava-se a repetição de sua expertise de atuação no SNPG para desenvolver também o Sistema Nacional de Formação Docente para a Educação Básica.

No entanto, a forma de atuação da agência no âmbito da educação básica não tem sido a mesma, quando comparada a sua atuação tradicional. Para destacar essa diferença e discutir os desafios dela decorrentes, analisaram-se as atas aprovadas nas 25 primeiras reuniões do Conselho Técnico-Científico da Educação Básica (CTC-EB). Essas atas compreendem as reuniões realizadas desde a instalação do conselho, entre fevereiro de 2008 e abril de 2013, período considerado suficiente para analisar neste ensaio a sedimentação das decisões então registradas. Essas atas foram solicitadas à Capes por meio do Serviço de Informação ao Cidadão, da então denominada Controladoria-Geral da União (CGU), atual Ministério da Transparência, Fiscalização e Controladoria-Geral da União, e foram recebidas por meio de arquivo anexado a uma mensagem de correio eletrônico. A mensagem recebida continha 25 arquivos em formato ".pdf", já numerados cronologicamente de 1 a 25. Contudo, computaram-se 
apenas 24 documentos distintos, uma vez que a ata identificada com 0 número 10 tinha o mesmo conteúdo da número 12. No seu conjunto, essas atas foram integralmente analisadas por sintetizarem as discussões do conselho, não se estabelecendo amostras desses documentos em função da sequência de raciocínio e por sua quantidade relativamente pequena.

O material coletado foi codificado, mantendo-se a numeração original que receberam, conforme ordem de realização das reuniões do CTC-EB. O conteúdo foi analisado com base na análise hermenêutica (MINAYO, 2013), procedendo-se: a) leitura flutuante (aproximação dos dados); b) preparação da planilha eletrônica; c) classificação dos trechos de forma categorizada por relevância; e d) realização de leitura transversal dos dados. $\mathrm{O}$ resultado desse esforço de análise está organizado nas seções dispostas a seguir.

\section{DO SONHO DE UM SISTEMA À REALIDADE DE UMA POLÍTICA}

A instalação do CTC-EB na Capes marcou o início de proposições visando à elaboração de ordenamento legal para amparar as ações do Ministério da Educação voltadas à formação de professores da educação básica. Naquele momento, conforme trecho presente na Ata 1 da reunião do referido conselho, havia uma expectativa de que "[...] o Conselho Técnico-Científico da Educação Básica [pudesse] emanar o Sistema Nacional de Formação Docente e, a partir do que existe e está sendo oferecido, indicar um novo caminho a ser seguido." (COORDENAÇÃO DE APERFEIÇOAMENTO DE PESSOAL DE NÍVEL SUPERIOR, 2008a, p.2).

A ideia era estruturar um sistema nacional de formação de professores da educação básica, entendido como o caminho para integração das ações do MEC nesse campo. Tal sistema abrangeria, então, a oferta dos cursos e programas existentes e outros a serem disponibilizados, de forma a potencializar seus resultados e eliminar esforços em duplicidade.

As pretensões sistêmicas, inclusive, não se restringiam à formação docente. Essas eram tidas como ponto de partida para a integração das ações do ministério de uma forma geral, uma vez que afetariam a qualidade 
da educação como um todo. Tal perspectiva assumia como pressuposto que a oferta de cursos de formação docente geraria impacto potencial, desde o Sistema Nacional de Avaliação da Educação Superior (Sinaes), na avaliação da qualidade dos cursos de licenciatura, até o Índice de Desenvolvimento da Educação Básica (Ideb). Esse último entendido como termômetro da repercussão da formação inicial e continuada na qualidade da educação básica, conforme expressou o então ministro da Educação:

[Cabe ao CTC-EB] refletir sobre as diretrizes das licenciaturas e sobre a possibilidade de uma forma de "alinhamento" ou uma combinação virtuosa de algumas ações do MEC, que hoje estão absolutamente fragmentadas. [...] A Capes fomentará a ampliação das licenciaturas e [de] programas, já estruturados, de formação continuada presencial e a distância do sistema público. [A] isso se chamará Sistema Nacional de Formação. [...] À Capes caberá organizar o fomento para atingir a expectativa de aumentar o contingente do professorado, em especial, formado nas universidades públicas. [...] A construção do Sistema Nacional de Educação [começa] com o Sistema Nacional de Formação. [O Ministro] destacou o valor do Sinaes e a reconstrução do Saeb [Sistema de Avaliação da Educação Básica]. [Defendeu] o Ideb, como parte da construção do Sistema Nacional de Educação, que permite que a União apoie as redes mais fragilizadas, equalizando oportunidades. (COORDENAÇÃO DE APERFEIÇOAMENTO DE PESSOAL DE NIVVEL SUPERIOR, 2008b, p.1-2)

Porém, tal proposta sistêmica de organização das ações de formação docente no âmbito federal repercutiu colateralmente na necessidade de discutir também as competências compartilhadas pelos entes federados, assim como a relação público-privada, em torno da qualidade e quantidade da oferta dos cursos de licenciatura e de programas de formação continuada. Além disso, a ideia de uma visão sistêmica do processo formativo de professores da educação básica terminou promovendo, ainda, a necessidade de uma reflexão mais ampla sobre as competências partilhadas entre órgãos do próprio ministério, tendo em vista que estava sob a responsabilidade do Conselho Nacional de Educação (CNE) a deliberação sobre a organização das licenciaturas, impactando qualquer tipo de ação da Capes voltada ao seu acompanhamento, mesmo que apenas sob o ponto de vista do fomento (resultados apresentados pelos cursos que receberam recursos públicos, por meio da Capes, para a formação de docentes). Tais impactos se materializavam não só no 
processo de organização acadêmica dos cursos a serem fomentados pela Capes, como também no próprio processo de gestão de sua qualidade, na medida em que possíveis ações avaliativas da Capes concorreriam com as do Sinaes. Assim, tal perspectiva sistêmica implicaria a necessidade de uma sintonia não só entre as competências de estados, municípios e da União, mas também no equacionamento das disputas entre instituições de educação superior (IES) públicas e privadas, bem como em mais diálogo entre a Capes, o CNE e o próprio Instituto Nacional de Estudos e Pesquisas Educacionais Anísio Teixeira (Inep).

É importante destacar ainda que, a despeito de as diretrizes acadêmicas de orientação, organização e avaliação dos cursos de licenciatura não terem sido discutidas ou implementadas pelo CTC-EB no período analisado, as ideias em torno da necessidade de se discutir a questão da qualidade dos cursos fomentados pela Capes estiveram presentes nos encontros do conselho. Tanto assim que na minuta de documento legal, a qual mais tarde se tornaria base para o texto do decreto responsável por instituir a Política Nacional de Formação dos Profissionais da Educação Básica, apensa à Ata 5 (COORDENAÇÃO DE APERFEIÇOAMENTO DE PESSOAL DE NÍVEL SUPERIOR, 2008c), o CTCEB trouxe a qualidade como eixo estruturante da perspectiva sistêmica proposta, de forma que o sistema nacional de formação permitisse planejar, ampliar e qualificar sua oferta. Por fim, coroando a concepção do sistema de formação de professores, a proposta do CTC-EB propôs expressamente no art. 11 da minuta de decreto (COORDENAÇÃO DE APERFEIÇOAMENTO DE PESSOAL DE NIIVEL SUPERIOR, 2008c, p. 11), que o MEC deveria assegurar coerência entre os cursos ofertados e os processos de avaliação da educação básica e superior com os demais programas do ministério, com o currículo da educação básica e com as diretrizes curriculares nacionais dos cursos de licenciatura, levando a uma articulação desejável entre essas ações.

Porém, não houve detalhamento sobre a execução prática de competência tão complexa, subentendendo-se que caberia à Capes a proeminência na condução do sistema em gestação. Esse ponto talvez tenha sido uma inobservância àquilo que Skocpol (2002) chamou de insulamento burocrático ou, numa tradução livre, nos interesses da 
burocracia em si, não necessariamente vinculados aos interesses da sociedade civil. A falta de definição sobre a condução desse processo de articulação de ações voltadas à formação de professores entre órgãos do MEC, aparentemente, gerou dúvidas acerca da reorganização das competências institucionais em questão. Não estava descartado o risco de que alguns dos órgãos envolvidos pudessem ser extintos ou esvaziados, fazendo com que o insulamento burocrático se evidenciasse nos interesses específicos desses agentes públicos. Diante desse quadro, ambiguamente, o delineamento da proposta do Sistema Nacional de Formação pareceu ser o início da sua dissolução pelo tensionamento das competências do CTC-EB/Capes em relação às competências do CNE, da Comissão Nacional de Avaliação da Educação Superior (Conaes) e do próprio Inep, sem que os limites e diferenças tivessem sido devidamente esclarecidos.

A proposta do sistema de formação, estabelecida na minuta do CTC-EB, implicaria em mexer com as bases da compartimentalização das ações do MEC entre seus órgãos vinculados - Capes, CNE e Inep - em prol da formação docente. Talvez, em função disso, tenha ocorrido certa mobilização interna para frear a proposta original, conforme expressou o registro da presença do presidente do CNE, na plenária do CTC-EB, para apresentar diversos esclarecimentos, bem como "desaconse[Ihar] a possível atribuição ao CTC-EB de homologar cursos superiores, que burocratizar[ia] o colegiado" (COORDENAÇÃO DE APERFEIÇOAMENTO DE PESSOAL DE NÍVEL SUPERIOR, 2008d, p. 3). Se implementada, tal competência poderia concorrer com as atribuições do próprio CNE e implicaria a adoção de um sistema avaliativo paralelo ao do Sinaes, específico para as licenciaturas.

Nesse contexto, ocorreu um recuo nos (re)arranjos organizativos em torno do Sistema Nacional de Formação. Primeiro, houve um redimensionamento das discussões em torno do papel reservado ao CTC-EB dentro da política de formação docente, o qual passou a ser apresentado como um aspecto separado da discussão que estava sendo travada para a organização legal e orçamentária do sistema de formação docente. Com isso, as pretensões de institucionalização do CTC-EB, então recém-criado, passaram a ser vistas como menos relevantes, podendo ser tratadas posteriormente. Segundo, não se aprofundou na divisão de 
competências da Capes como protagonista do sistema em formação, em sua interface com competências assumidas pelo Inep na condução do Sinaes, bem como na relação ainda muito confusa entre as competências do CNE e do CTC-EB na definição de diretrizes de organização de cursos de licenciatura. Terceiro, priorizou-se o argumento de urgência do MEC/Capes para a definição do decreto a ser sancionado, visando regular a atuação da agência e a execução do seu orçamento, reservado à formação docente da educação básica, independentemente de se ter ou não esse sistema.

Assim, a despeito dos argumentos a favor do sistema de formação docente, os quais deslancharam os trabalhos do CTC-EB, venceu o entendimento "de que não falar em sistema e sim em política [de formação docente] não era um recuo do CTC-EB. [Essa decisão deveria ser visualizada como um] 'considerado' inicial que apontasse para o Sistema Nacional, [representando] um avanço e não um recuo" (COORDENAÇÃO DE APERFEIÇOAMENTO DE PESSOAL DE NÍVEL SUPERIOR, 2008e, p.1).

No entanto, perdeu força a perspectiva tradicional de atuação da Capes em prol da qualidade de cursos de formação sob sua reponsabilidade. No caso da formação de professores para a educação básica, a organização da oferta não foi precedida de uma diretriz acadêmica estabelecida pela Capes, mecanismos internos de acompanhamento ou definições de padrão de qualidade. Foram assumidos os critérios nem sempre claros do Sinaes para a avaliação de cursos superiores (SOUZA, 2015), sem observar as especificidades das áreas de conhecimento, cuidado adotado pela Capes na condução de seus processos avaliativos.

A partir de então, a perspectiva sistêmica dos programas de formação de profissionais da educação básica foi suprimida nas discussões que se seguiram no CTC-EB, corroborando para o entendimento de que as decisões que envolvem as relações entre o Estado e a sociedade civil são eminentemente políticas, mesmo quando revestidas de argumentos técnico-científicos. Em lugar do Sistema Nacional de Formação de Professores, foi sugerida e aprovada a Política de Formação Docente, organizada federativamente por meio dos Fóruns Estaduais Permanentes de Apoio à Formação Docente, e integrada por IES públicas e privadas sem fins lucrativos. No que se referiu à perspectiva de qualidade dos 
cursos ofertados, consolidou-se o entendimento de que "a graduação é avaliada pelo Inep." (COORDENAÇÃO DE APERFEIÇOAMENTO DE PESSOAL DE NÍVEL SUPERIOR, 2013, p. 4). Aspectos específicos sobre cursos de licenciaturas não tiveram espaço para discussões ou novos encaminhamentos.

Dessa forma, o Sinaes e seus parâmetros foram apropriados acriticamente no âmbito da Política Nacional de Formação de Profissionais do Magistério da Educação Básica, Decreto $n^{\circ}$ 6.755, de 29 de janeiro de 2009 , estabelecendo-se no seu art. $10^{\circ}, \S 2^{\circ}$ que os programas de formação inicial, apoiados com recursos da Capes, à revelia de qualquer critério acadêmico, precisariam, apenas, ter avaliação positiva no Sinaes. (BRASIL, 2009).

\section{O SISTEMA NACIONAL DE FORMAÇÃO DE PROFESSORES E 0 ESTATUTO DA CAPES}

0 mais recente estatuto da Capes, aprovado em 2012, ainda mantém a expectativa de atuação do CTC-EB em um sistema nacional de formação de professores (BRASIL, 2012). Nesse sentido, embora o CTCEB/Capes tivesse recuado na estruturação de um sistema de formação, as suas competências legais o impulsionavam em prol da construção desse sistema.

Todavia, desde a instalação do conselho, as iniciativas voltadas à estruturação dessa competência sempre provocaram reações da burocracia, tendo em vista que a operacionalização de tal competência esbarraria no estabelecimento de parâmetros avaliativos dos cursos de graduação, a cargo do Sinaes. Justifica esse entendimento, a presença de representantes do Inep e da Secretaria de Regulação e Supervisão da Educação Superior do MEC (Seres) nas reuniões do CTC-EB para sugerir que o conselho tivesse atuação

[...] semelhante à OAB nos cursos de Direito, e ao Conselho Federal de Biologia nos cursos de Biologia, que dão pareceres após a avaliação feita pelo Inep. Não estão previstas manifestações nas autorizações, somente 
nos reconhecimentos e na renovação de reconhecimento. Foi informado que essa é uma disposição que está já escrita à espera de um comando do Conselho para se tornar realidade. (COORDENAÇÃO DE APERFEIÇOAMENTO DE PESSOAL DE NIVEL SUPERIOR, 2010a, p.4-5)

A despeito da decisão sobre a política de formação de professores, as competências do CTC-EB continuavam no centro dos embates internos da burocracia do MEC, sem que houvesse uma predisposição política para uma discussão mais ampla sobre a organização do ministério em torno da formação docente e da regulação de sua qualidade.

O colegiado, por meio de alguns de seus membros, reforçou a questão da avaliação dos cursos de formação inicial, de programas de formação continuada e da criação de "uma cultura de licenciaturas e de pedagogias que tenham um nivel de excelência reconhecido, e que possam, positivamente, contaminar outras instituições que as ofereçam" (COORDENAÇÃO DE APERFEIÇOAMENTO DE PESSOAL DE NIIVEL SUPERIOR, 2010b). Porém, não havia espaço político para o CTCEB realizar aquilo que the cabia: verificar a eficiência, eficácia e efetividade dos cursos dentro da política de formação docente. Dessa forma, a possibilidade de ações do conselho em prol da implementação efetiva de uma política de qualidade para a formação de professores foi substituída pela sua não ação, seguindo a dinâmica considerada por Souza (2006) e Muller e Surel (2002) sobre a institucionalização de políticas públicas.

Os registros em atas deixam entrever que o entendimento dos dirigentes da Capes foi no sentido de que o estabelecimento de parâmetros para avaliação de licenciaturas fomentadas pela agência poderia interferir na divisão de papéis avaliativos partilhados com o Inep, posição anteriormente já evitada. Nesse sentido, conforme ratificou o trecho da Ata 16 (COORDENAÇÃO DE APERFEIÇOAMENTO DE PESSOAL DE NÍVEL SUPERIOR, 2010b, p.4), transcrito a seguir, foi informado

[...] que a Capes avalia pós-graduação, mas quem avalia a graduação é o Inep. Assim, a Capes não pode avaliar as licenciaturas, mas sim programas institucionais de formação [...] pensando nas exigências da CGU, a Capes decidiu contratar, pela Unesco, consultores para verificar se o caminho está correto. Essa ação da Diretoria de Educação Básica, chamada de 
acompanhamento, [...][ocorrerá] no final de outubro, e em novembro será elaborado um roteiro [...] os analistas serão divididos para visitar todas as instituições que estão oferecendo cursos pelo Parfor [Plano Nacional de Formação de Professores] e verificar de que forma esses cursos estão sendo ministrados e quais as dificuldades. Informalmente já foram feitas algumas visitas.

Considerando os posicionamentos constantes desses fragmentos e do próprio conteúdo da Ata da $16^{a}$ Reunião do CTC-EB (COORDENAÇÃO DE APERFEIÇOAMENTO DE PESSOAL DE NIVEL SUPERIOR, 2010b), entendeu-se que a perspectiva de separação de competência entre Capes e Inep levou a primeira a agir autofagicamente em relação ao CTC-EB, pois (i) o conselho deixaria de estabelecer parâmetros avaliativos para balizar a concessão do fomento pela Capes aos cursos de formação inicial de docentes, assumindo o entendimento de que esses estariam circunscritos ao Sinaes, conforme definido pelo Decreto que instituiu a política de formação de professores; (ii) a avaliação das ações de fomento da Capes - exigida pelos órgãos de controle e prevista no próprio estatuto da agência - seria realizada por um processo de acompanhamento realizado por consultores, sem envolver o CTC-EB; e (iii) os parâmetros de avaliação dos programas de formação continuada - que por sua natureza não são avaliados pelo Sinaes - ficaram fora do contexto de discussão da qualidade dos programas formativos fomentados pela Capes.

\section{DESAFIOS DA CAPES NA FORMAÇÃO DE PROFESSORES}

A partir desse contexto, identificaram-se três conjuntos de desafios que precisam ser enfrentados pela Capes na condução da política de formação de professores da educação básica. 0 primeiro conjunto refere-se à concatenação das ações emergenciais de curto prazo, previstas no inciso III do art. 11 da Política de Formação Docente (BRASIL, 2009), com as de longo prazo, previstas nos incisos IV, VII e IX do art. $3^{\circ}$ do mesmo documento legal. Apesar de esse decreto ter sido revogado, é necessário reconhecer que a prática das ações da Capes enfatizou a formação emergencial dos professores da educação básica (sentido presente) sem oferecer respostas claras sobre a formação de pessoal para atuar na educação básica (perspectiva de futuro). O Plano Nacional 
de Formação de Professores (Parfor), que envolve parte das ações da Universidade Aberta do Brasil (UAB) no que tange à formação presencial e continuada a distância, mais o Parfor Presencial, que abrange a formação inicial na modalidade presencial de professores, e os cursos presenciais de formação continuada executados diretamente pelo MEC, ocuparamse prioritariamente das qualificações dos atuais docentes, no modelo atual de formação. Sobre os futuros docentes e a evolução dos cursos formadores, as ações foram pouco evidenciadas, conforme corroborou o CTC-EB ao destacar a "[...] necessidade de debate pela Capes e pelos órgãos do Ministério da Educação de diretrizes políticas para a formação de professores, não centradas em ações emergenciais." (COORDENAÇÃO DE APERFEIÇOAMENTO DE PESSOAL DE NIVVEL SUPERIOR, 2010c, p.2).

Essa inconsistência entre a proposta de uma ampla política de formação de professores e a sua caracterização por ações de cunho emergencial não pareceu gerar consequências imediatas num contexto em que existe demanda reprimida por formação inicial dos atuais professores. ${ }^{1}$ Porém, no longo prazo, tal omissão poderá levar a possíveis prejuízos tendo em vista que: a) a burocracia, em sua disputa por orçamento e prestígio, pode adotar uma visão míope, transformando um programa emergencial em permanente; b) a desarticulação entre as ações de curto e longo prazo pode promover a perpetuação de programas pulverizados e a crescente duplicação de esforços; e c) a inexistência de estratégias de longo prazo, voltada à formação dos docentes atuais e futuros, pode estagnar a perspectiva de inovação de uma política ainda recente.

Vale destacar, também, que a revogação do Decreto n 6.755/09, ao contrário de minimizar esse desafio, o catalisa. 0 novo regulamento prevêa instituição do "Programa Nacional de Formação de Profissionais da Educação Básica", conforme explicitado no Art. $3^{\circ}$ do Decreto $n^{\circ}$ 8.752/16, de 9 de maio de 2016 (BRASIL, 2016). De acordo com o vigente ordenamento legal, os atuais programas regulados pela legislação anterior (aparentemente referindo-se à UAB e ao Parfor Presencial) perderão efeito quando encerrado seus atuais compromissos. Dessa forma questiona-se: como será então a ação da Capes no campo da formação de professores? 
Um segundo conjunto de desafios que precisa ser enfrentado pela Capes no desenvolvimento da política de formação de professores referese ao papel dos Fóruns Estaduais Permanentes de Apoio à Formação Docente. A criação desses fóruns visou dar cumprimento aos objetivos da política de formação de docentes para a educação básica, e teve por finalidade concretizar o regime de colaboração entre a União, os estados, o Distrito Federal e os municípios, por meio de planos estratégicos de formação inicial e continuada dos profissionais do magistério para as redes públicas da educação em suas respectivas Unidades da Federação. Porém, apesar de sua natureza colegiada e complexa, as decisões, sintetizadas no plano estratégico, vinham sendo submetidas ao MEC/Capes sem que o processo avaliativo desse plano tenha sido definido pelo CTC- EB. Talvez em função disso, a edição do Decreto ${ }^{\circ}$ 8.752/16 criou um comitê gestor nacional que passou a compartilhar atribuições que eram do fórum. No entanto, existe um vácuo sobre o papel reservado à Capes nessa nova configuração.

Por fim, um terceiro conjunto de desafios que precisa ser observado refere-se à questão da qualidade dos cursos de licenciatura apoiados com os recursos da Capes, e sua distinção em relação aos demais cursos que não são apoiados com recursos de fomento da agência, mas que também formam professores. Adicionalmente, também precisa ser mais bem observada a qualidade dos cursos de formação continuada e a interação desses processos avaliativos com aquele desenvolvido pelo Inep por meio do Sinaes.

\section{CONSIDERAÇÕES FINAIS}

O propósito deste ensaio foi favorecer o diálogo sobre a atuação da Capes na condução da Política Nacional de Formação de Professores da Educação Básica. Considerando o conjunto de atas do CTC-EB, a análise apresentada destacou os embates de interesse circunscritos à burocracia do MEC em torno da criação de um sistema nacional de formação de professores. A principal linha de argumentação pautouse nos enfrentamentos entre uma possivel avaliação das licenciaturas fomentadas pela Capes e as avaliações do Sinaes para cursos de 
graduação, em geral, e de licenciatura, em específico. Em consequência pontuou-se a não-ação da Capes em torno da orientação de um padrão de qualidade para as licenciaturas oferecidas no âmbito da Política Nacional de Formação de Professores. Desse contexto, destacaram-se três desafios a serem enfrentados pela Capes para superar as lacunas decorrentes de sua atuação: a questão da formação de professores numa perspectiva de longo prazo, em complementação às ações emergenciais de formação atualmente desenvolvidas, o papel reservado à Capes dentro do novo quadro legal que orienta a política de formação docente e, finalmente, a questão da qualidade dos programas de formação inicial e continuada, tendo em vistas os princípios tradicionais de atuação da Capes, que atrela a concessão de fomento a processos avaliativos.

\section{Referências}

BRASIL. Lei n 11.502, de 11 de julho de 2007. Modifica as competências e a estrutura organizacional da fundação Coordenação de Aperfeiçoamento de Pessoal de Nível Superior - Capes, de que trata a Lei $n^{\circ}$ 8.405, de 9 de janeiro de 1992; e altera as Leis nº 8.405, de 9 de janeiro de 1992, e 11.273, de 6 de fevereiro de 2006, que autoriza a concessão de bolsas de estudo e de pesquisa a participantes de programas de formação inicial e continuada de professores para a educação básica. Diário Oficial da União, Brasília, 12 jul. 2007. Disponível em: <http://www.planalto.gov.br/ ccivil_03/_ato2007-2010/2007/Lei/L11502.htm>. Acesso em: 7 dez. 2011.

Decreto $\mathrm{n}^{\circ}$ 6.755, de 29 de janeiro de 2009. Institui a Política Nacional de Formação de Profissionais do Magistério da Educação Básica, disciplina a atuação da Capes no fomento a programas de formação inicial e continuada, e dá outras providências. Diário Oficial da União, Brasília, 30 jan. 2009. Disponível em: <www.planalto.gov.br/ccivil_03/_ato20072010/2009/decreto/d6755.htm>. Acesso em: 24 out. 2016.

Decreto $n^{\circ}$ 7.692, de 2 de março de 2012. Aprova o Estatuto e o Quadro Demonstrativo dos Cargos em Comissão da Coordenação de Aperfeiçoamento de Pessoal de Nível Superior - CAPES, e remaneja cargos 
em comissão. Diário Oficial União, Brasília, DF, 3 mar. 2012. Disponível em: <www.planalto.gov.br/ccivil_03/_ato2011-2014/2012/decreto/d7692. htm>. Acesso em: 19 jul. 2013.

. Decreto $\mathrm{n}^{\circ}$ 8.752, de 9 de maio de 2016. Dispõe sobre a Política Nacional de Formação dos Profissionais da Educação Básica. Diário Oficial da União, Brasília, 10 maio 2016. Disponível em: <http://www.planalto. gov.br/ccivil_03/_Ato2015-2018/2016/Decreto/D8752.htm>. Acesso em: 24 out. 2016.

COORDENAÇÃO DE APERFEIÇOAMENTO DE PESSOAL DE NÍVEL SUPERIOR. Coordenação Executiva dos Órgãos Colegiados. Conselho Técnico Científico da Educação Básica. Ata da $\mathbf{1}^{\mathbf{a}}$ Reunião Ordinária. Brasília, DF, 14 fev. 2008a.

. Coordenação Executiva dos Órgãos Colegiados. Conselho Técnico

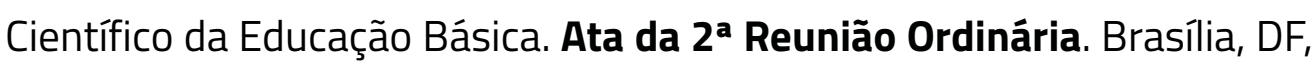
11 mar. 2008b.

. Coordenação Executiva dos Órgãos Colegiados. Conselho Técnico Científico da Educação Básica. Ata da $5^{a}$ Reunião Ordinária. Brasília, DF, 24 set. 2008 c.

. Coordenação Executiva dos Órgãos Colegiados. Conselho Técnico Científico da Educação Básica. Ata da $\mathbf{6}^{\mathbf{a}}$ Reunião Ordinária. Brasília, DF, 27 nov 2008d.

. Coordenação Executiva dos Órgãos Colegiados. Conselho Técnico

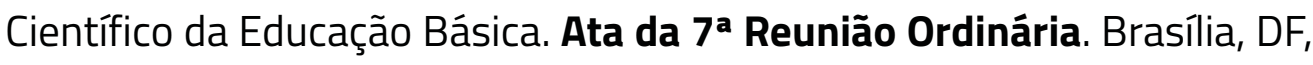
08 dez. 2008e.

. Coordenação Executiva dos Órgãos Colegiados. Conselho Técnico Científico da Educação Básica. Ata da 14 a Reunião Ordinária. Brasília, DF, 01 jul. 2010a.

. Coordenação Executiva dos Órgãos Colegiados. Conselho Técnico Científico da Educação Básica. Ata da 16ª Reunião Ordinária. Brasília, DF, 05 out. 2010 b. 
. Coordenação Executiva dos Órgãos Colegiados. Conselho Técnico Científico da Educação Básica. Ata da $17^{a}$ Reunião Ordinária. Brasîlia, DF, 08 dez. 2010c.

. Coordenação Executiva dos Órgãos Colegiados. Conselho Técnico Científico da Educação Básica. Ata da 25a Reunião Ordinária. Brasília, DF, 16 abr. 2013.

MINAYO, M. C.S. 0 desafio do conhecimento: pesquisa qualitativa em saúde. $13^{a}$ ed. São Paulo: Hucitec, 2013. 407p.

MULLER, P.; SUREL, Y. A análise das políticas públicas. Pelotas: Educat, 2002. 156p.

SKOCPOL, T. Bringing the state back instrategies of analysis in current research. In: EVANS, P.; RUESCHEMEYER, D.; SKOCPOL, T. (Eds.). Bringing the state back in. Cambridge: Cambridge University Press, 2002 (Edição eletrônica).

SOUZA, C. Políticas públicas: uma revisão da literatura. Sociologias, Porto Alegre, ano 8, n. 16, p. 20-45, jul./dez. 2006.

SOUZA, V. C. Entre o explícito e o latente: revelações do Parfor e do Sinaes sobre a qualidade dos cursos de pedagogia, 2015. 295 p. Tese (Doutorado em Educação) - Universidade de Brasília, Brasília, 2015.

Recebido em 24/10/2016 Aprovado em 07/12/2016 